Sabine Bergstermann

Stammheim 


\section{Quellen und Darstellungen}

\section{zur}

\section{Zeitgeschichte}

Herausgegeben vom Institut für Zeitgeschichte

Band 112 
Sabine Bergstermann

\section{Stammheim}

Eine moderne Haftanstalt als Ort

der Auseinandersetzung zwischen Staat und RAF

\section{DE GRUYTER \\ OLDENBOURG}


ISBN 978-3-11-040482-1

E-ISBN (PDF) 978-3-11-040499-9

E-ISBN (EPUB) 978-3-11-040510-1

ISSN 0481-3545

\section{Library of Congress Cataloging-in-Publication Data}

A CIP catalog record for this book has been applied for at the Library of Congress.

\section{Bibliografische Information der Deutschen Nationalbibliothek}

Die Deutsche Nationalbibliothek verzeichnet diese Publikation in der Deutschen Nationalbibliografie; detaillierte bibliografische Daten sind im Internet über http://dnb.dnb.de abrufbar.

(c) 2016 Walter de Gruyter GmbH Berlin/Boston

Titelbild: Aus Stammheim - eine Gebäudemonographie von Andreas Magdanz, www.andreasmagdanz.de

Einbandgestaltung: hauser lacour

Druck und Bindung: Hubert \& Co. GmbH \& Co. KG, Göttingen

(@) Gedruckt auf säurefreiem Papier

Printed in Germany

www.degruyter.com 